\title{
Effect of White Wine Consumption on Oxidative Stress Markers and Homocysteine Levels
}

\author{
D. RAJDL, J. RACEK, L. TREFIL, K. SIALA ${ }^{1}$ \\ Institute of Clinical Chemistry and Hematology, University Hospital and Charles University, \\ Faculty of Medicine in Pilsen, Czech Republic and ${ }^{1}$ Department of Internal Medicine, St Helier \\ Hospital in London, United Kingdom
}

Received January 2, 2006

Accepted March 16, 2006

On-line available March 23, 2006

\begin{abstract}
Summary
The aim of this study was to assess the influence of regular daily consumption of white wine on oxidative stress and cardiovascular risk markers. Forty-two healthy male volunteers consumed $375 \mathrm{ml}$ of white wine daily. Each participant provided three venous blood samples (before wine consumption, following the wine consumption period and again a month later). Levels of superoxide dismutase, glutathione peroxidase, reduced glutathione, total antioxidant capacity, total cholesterol, HDL-cholesterol, apolipoprotein A I, apolipoprotein B, triglycerides, paraoxonase 1, C-reactive protein, homocysteine, thiobarbituric acid reactive substances (TBARS) and advanced oxidation protein products (AOPP) were measured. Immediately following the month of white wine consumption there was a significant increase in HDL-cholesterol $(p<0.0001)$, paraoxonase $1(p<0.001)$, glutathione peroxidase $(p<0.001)$ and reduced glutathione $(\mathrm{p}<0.01)$ levels, a decrease in superoxide dismutase activities $(\mathrm{p}<0.0001)$, and a decrease in oxidation protein products $(p<0.001)$ and TBARS $(p<0.05)$ concentrations. However, there was also a clear increase in homocysteine $(p<0.0001)$ after a month of white wine consumption. The results of our non-placebo controlled trial suggest that regular daily white wine consumption is associated not only with both antioxidative and antiatherogenic effects but also with a potentially proatherogenic increase of homocysteine concentrations.
\end{abstract}

\section{Key words}

White wine $\bullet$ Oxidative stress $\bullet$ Homocysteine

\section{Introduction}

Complications of atherosclerosis represent a leading cause of morbidity and mortality worldwide. Several epidemiological (Maclure 1993) and experimental (Rimm et al. 1999) studies have proposed that mild to moderate alcohol consumption is associated with a decreased risk of atherosclerosis. It is still not clear, whether a particular type of alcoholic beverage (red or white wine, beers or spirits) is important in this context (Di Castelnuovo et al. 2002, Klatsky et al. 1997, Truelsen et al. 1998) or not (van der Gaag et al. 1999) and there is no consensus on the recommended amount (if any) of daily consumed alcohol (Goldberg et al. 2001). Probably the most discussed issue is the so-called "French paradox" (i.e. relatively low prevalence of coronary heart 
disease in southern France despite a high intake of saturated fats). This regional variation has not yet been explained satisfactorily. It is often associated with an increased consumption of (red) wine and a typical Mediterranean diet (i.e. relatively high consumption of fruit and vegetables, fish and olive oil) and specific lifestyle (Goldberg et al. 2001). There is growing evidence that red and white wines contain some active, usually polyphenolic substances (quercetin, tyrosol, tannic acid, caffeic acid, catechin, resveratrol etc.) that have proven their anti-atherosclerotic and anti-oxidative effects in vitro (Demrow et al. 1995, Saija et al. 1995), ex vivo (Cui et al. 2002, Flesch et al. 1998) and in vivo (Aviram and Fuhrman 2002, Perez et al. 2002).

Various mechanisms of action have been proposed for the manner in which moderate wine consumption exerts its protective action against atherosclerosis. The most important of these are an increase in high-density lipoprotein-cholesterol (HDL) (Maclure 1993, Rimm et al. 1999, van der Gaag et al. 1999) and apolipoprotein A-I (apoA) (Rimm et al. 1999), and protection against the oxidation of low-density lipoproteins (LDL) (Aviram and Fuhrman 2002). Reactive oxygen and nitrogen species (RONS) may cause chemical alterations of biomolecules (lipids, proteins, DNA, carbohydrates) and the redox state of the whole organism is maintained by a complex of mechanisms. Scavenging enzyme activities $(\mathrm{Cu}-\mathrm{Zn}$ superoxide dismutase, SOD, glutathione peroxidase, GPx) reflect antioxidant defense status. Glutathione is the most abundant intracellular antioxidant. The majority of malondialdehyde (MDA) in plasma originates during unsaturated fatty acids peroxidation. Among the different analytical methods established, the reaction with thiobarbituric acid (thiobarbituric acid reactive substances, TBARS) is the most widely used (Jentzsch et al. 1996). Although the reaction is not specific for MDA only, it was shown that the majority of TBARS originate in lipid peroxidation (Lefevre et al. 1998). Advanced oxidation protein products (AOPP) are proteins, predominantly albumin and its aggregates, damaged by oxidative stress (Kalousová et al. 2005). They are formed mainly by hypochloric acid and chloramines resulting from neutrophil myeloperoxidase activity. They are referred to as markers of oxidative stress and neutrophil activation. AOPP were described as an independent risk factor for coronary artery disease (Kalousová et al. 2005). Paraoxonases (PON) are a group of enzymes that could be important in LDL protection against oxidation and probably exert antioxidative and antiatherogenic effect ( $\mathrm{Ng}$ et al. 2005). PON activities probably rise as a consequence of daily moderate alcohol consumption (Rao et al. 2003, Sierksma et al. 2002, van der Gaag et al. 1999). However, there are several known adverse effects of moderate alcohol consumption such as an increase in triglycerides (TG) and homocysteine (Hcy) and possibility of addiction to alcohol (van der Gaag et al. 2000a). To our knowledge, the effect of moderate white wine consumption on oxidative stress markers and Hcy in humans has not yet been examined. The differences between red and white wines with regard to their possible antioxidative and antiatherogenic properties are still being discussed. It is quite obvious that a majority of red wines have a greater content of polyphenols in comparison with white wines (Tselepis et al. 2005) and there are some studies that have confirmed the superiority of red wines in some antioxidative effects (Landrault et al. 2001, Tselepis et al. 2005). However, there are also studies that have reported no differences in the effects of red and white wines on endothelial function (Whelan et al. 2004). It has been published that white wines have significantly lower concentrations of ochratoxin A and there is a north to south gradient in concentrations of this potentially dangerous toxin (Bellí et al. 2002).

Thus white wines from the Czech Republic can provide some special properties. As white wines are popular in the Czech Republic and its potential role in protection against atherosclerosis complications development was not studied as thoroughly as in the case of red wines, we decided to examine the complex effects of white wine from the Czech Republic. In this study we have aimed to assess whether regular consumption of white wine has antioxidative effects and how it influences markers of cardiovascular risk in middle-aged men. We have intended to perform a comparative study with minimal possible interference with each participant's own habits, so that the results could be applicable for a more general recommendation.

\section{Methods}

\section{Subjects}

Sixty-two volunteers were recruited from the Pilsner region (Czech Republic). Each potential participant of this study was thoroughly informed about the study protocol, signed an informed consent, filled an alcohol consumption questionnaire and underwent an initial laboratory and clinical examination. We excluded 
Table 1. Characteristics of the study group (42 participants).

\begin{tabular}{|c|c|c|c|}
\hline & \multicolumn{3}{|c|}{ Visit } \\
\hline & $\mathbf{0}$ & 1 & 2 \\
\hline Age (years) & & $41.9 \pm 9.7$ & \\
\hline Body mass index $\left(\mathrm{kg} / \mathrm{m}^{2}\right)$ & $26.10 \pm 2.28$ & $26.10 \pm 2.33$ & $26.10 \pm 2.37$ \\
\hline Systolic blood pressure (mm $\mathrm{Hg}$ ) & $128 \pm 10.3$ & $125.6 \pm 10.32$ & $121.7 \pm 9.3$ \\
\hline Diastolic blood pressure (mm $\mathrm{Hg}$ ) & $83 \pm 7.20$ & $82.1 \pm 7.74$ & $81.9 \pm 7.90$ \\
\hline Alcohol consumption (g/day) & $19.0 \pm 13.34$ & $49.5 \pm 13.91 * * *$ & $19.9 \pm 15.55 \dagger \dagger \dagger$ \\
\hline Aspartate aminotransferase ( $\mu \mathrm{kat} / \mathrm{l})$ & $0.43 \pm 0.10$ & $0.45 \pm 0.10 *$ & $0.41 \pm 0.08 \dagger \dagger$ \\
\hline Alanine aminotransferase ( $\mu \mathrm{kat} / \mathrm{l})$ & $0.50 \pm 0.18$ & $0.55 \pm 0.20 * *$ & $0.51 \pm 0.15 \dagger$ \\
\hline$\gamma$-Glutamyltransferase ( $\mu$ kat/l) & $0.49 \pm 0.30$ & $0.51 \pm 0.28$ & $0.48 \pm 0.26$ \\
\hline$\alpha$-Amylase ( $\mu$ kat $/ l)$ & $2.18 \pm 0.68$ & - & - \\
\hline Cholesterol (mmol/l) & $5.62 \pm 1.11$ & $5.67 \pm 1.05$ & $5.63 \pm 1.02$ \\
\hline$H D L(\mathrm{mmol} / \mathrm{l})$ & $1.49 \pm 0.27$ & $1.62 \pm 0.32 * * *$ & $1.5 \pm 0.29 \dagger \dagger \dagger$ \\
\hline apoA $(g / l)$ & $1.47 \pm 0.14$ & $1.54 \pm 0.16 * *$ & $1.5 \pm 0.14 \dagger$ \\
\hline $\operatorname{apoB}(g / l)$ & $0.95 \pm 0.25$ & $0.95 \pm 0.25$ & $0.94 \pm 0.23$ \\
\hline atherogenic index of plasma & $2.94 \pm 1.10$ & $2.67 \pm 1.04 * *$ & $2.9 \pm 1.07 \dagger$ \\
\hline Triglycerides (mmol/l) & $1.53 \pm 1.10)$ & $1.55 \pm 0.73$ & $1.53 \pm 0.67$ \\
\hline PON $(U / l)$ & $87.6 \pm 37.87$ & $92.6 \pm 36.51 * * *$ & $93.89 \pm 35.7$ \\
\hline Fibrinogen $(g / l)$ & $3.22 \pm 0.56$ & $3.34 \pm 0.60$ & $3.53 \pm 0.64$ \\
\hline$u C R P(m g / l)$ & $0.93 \pm 0.66$ & $1.21 \pm 1.23$ & $0.99 \pm 0.91$ \\
\hline Homocysteine ( $\mu$ mol/l) & $12.34 \pm 3.36$ & $14.4 \pm 5.16 * * *$ & $13.5 \pm 4.90 \dagger \dagger$ \\
\hline Glucose (mmol/l) & $4.73 \pm 0.55)$ & $4.69 \pm 0.51)$ & $4.81 \pm 0.52$ \\
\hline
\end{tabular}

Data are expressed as mean \pm S.D. Visit $0=$ initial values before wine consumption period (WCP); visit $1=$ values next day after finishing WCP; visit 2 = values 1 month after WCP. (**,***): Statistically significantly different from visit 0 : $p<0.05(p<0.01, p<0.001)$. $\dagger(\dagger+,+\uparrow+)$ : Statistically significantly different from visit 1 : $p<0.05(p<0.01, p<0.001)$

nine volunteers due to abnormal laboratory results, ten were excluded due to pre-existing chronic disorders (hypertension, hypothyroidism) and one was excluded after discontinuation of the study due to non-compliance (ingestion of multivitamin tablets). Of the remaining 42 volunteers eight were smokers (5-40 cigarettes/day, mean 15 cigarettes/day). None of these participants took any medication or supplements with vitamins or other antioxidants on a regular basis. The characteristics of our study group are summarized in Table 1.

\section{Wine characteristics}

We selected a dry white wine produced in the Czech Republic (region of Mikulov, Müller Thurgau, year 2001) with a typical content of total polyphenolic compounds (268.7 mg/l), catechin (9 mg/l), epicatechin $(3.7 \mathrm{mg} / \mathrm{l})$, gallic acid $(4.05 \mathrm{mg} / \mathrm{l})$ and resveratrol $(0.19$ $\mathrm{mg} / \mathrm{l})$.

Polyphenolic compounds in the studied wine were determined by a photometric method (Basařová and
Černá 1974). Levels of gallic acid, catechin, epicatechin and resveratrol were determined by a HPLC method with DAD detection (Tř́ska et al. 2004). The alcohol content was $11.51 \%$ vol. and total antioxidant capacity of 4.18 $\mathrm{mmol} / 1$.

\section{Study protocol}

The study was approved by the local ethical committee and was carried out from October to December 2002. The study was designed as an interventional cohort study. Each enrolled volunteer visited our Institute three times: before (visit 0 ) and after (visit 1) white wine consumption period (WCP), and one month after WCP (visit 2). On each visit blood pressure, body weight and fasting blood samples of enrolled volunteers were measured and an alcohol consumption questionnaire was filled out. On visit 0 , the volunteers were filtered as mentioned above. All enrolled participants were asked to consume $375 \mathrm{ml}$ of white wine with their dinner daily for one month and to maintain 
their usual lifestyle (including alcohol consumption) during the whole study. The first visit was planned for the day after the last wine bottle had been consumed (between 0:06 and 0:08 h, i.e. 8 to 12 hours after wine consumption). Compliance to the study protocol was checked on visit 1 and 2 by a discussion with each participant. The consumption of different alcoholic beverages during the study was as follows (mean \pm S.D.): Visit 0 - 19.0 013.34 grams of ethanol per day, from this amount $6.7 \pm 7.9 \mathrm{~g} / \mathrm{day}$ was from wine (either red or white), $10.0 \pm 9.58 \mathrm{~g} /$ day from beer and $2.2 \pm 3.51 \mathrm{~g} /$ day from spirits. Visit 1: $49.5 \pm 13.91$ grams of ethanol per day, from this amount $38.1 \pm 7.84 \mathrm{~g}$ /day was from wine (33 $\mathrm{g} /$ day from administered white wine, the rest from either red or white wine), $9.2 \pm 10.03 \mathrm{~g} /$ day from beer and $2.3 \pm 3.73 \mathrm{~g} /$ day from spirits. Visit 2: $19.9 \pm 15.55$ grams of ethanol per day, from this amount $7.8 \pm 9.14 \mathrm{~g}$ /day from wine (either red or white), $9.8 \pm 9.72 \mathrm{~g} /$ day from beer and $2.3 \pm 3.71 \mathrm{~g} /$ day from spirits. There was a significant decrease in consumption of ethanol from extra wine $(\mathrm{CI}=$ 0.4 to $3.6 \mathrm{~g}$ ) and beer $(\mathrm{CI}=1.7$ to $4.0 \mathrm{~g}$ ) between visit 0 and visit 1 . Cardiovascular risk markers were individually evaluated and, if required, lifestyle changes and future control visits in our Institute were recommended after end of the study. The absence of a control group was motivated by a virtual impossibility of a complex white wine drinking simulation (psychosocial context, possible additive/ antagonistic effect of ethanol and other active substances, taste, color, odor of a control drink). The design of our study (A-B-A), together with recommendation to maintain the usual lifestyle led us to presumption that each participant can be a control to himself (visit 0 and visit 2 as control values). However, possible time-dependent changes (e.g. seasonal influences) in measured parameters cannot be controlled with this design.

Daily ethanol intake was estimated as follows: grams of ethanol/day $=$ volume of beverage $(\mathrm{dl}) \mathrm{x}$ strength (vol./vol.: \%) x 0.8 (specific gravity of ethanol) / frequency of consumption in days (the alcohol consumption questionnaire offered four possibilities: daily, weekly, monthly and yearly for each type of beverage: wine, beer and spirits).

\section{Analytical methods}

Fasting venous blood was withdrawn into test tubes with sodium heparin and into tubes containing gel and clot activator (Vacuette, Greiner, Kremsmünster, Austria). All samples were processed within 1 hour of collection and stored at $-80^{\circ} \mathrm{C}$ until analysis.

Serum levels of aspartate aminotransferase (AST, Dialab, Vienna, Austria), alanine aminotransferase (ALT, Dialab, Vienna, Austria), $\gamma$-glutamyltransferase (GMT, Human, Wiesbaden Germany), total cholesterol (TC, Human, Wiesbaden, Germany), HDL-cholesterol (HDL, Roche Diagnostics, Mannheim, Germany), apolipoproteins A-I and B (apoA, apoB, Tina-quant, Roche Diagnostics, Mannheim, Germany), triglycerides (TG, Human, Wiesbaden, Germany), ultra-sensitive uCRP (uCRP, Orion Diagnostica, Espoo, Finland), fibrinogen (Fib, Roche Diagnostics, Mannheim, Germany), homocysteine (Hcy, Abbott, Chicago, IL, USA, on IMx Analyzer), superoxide dismutase (SOD, EC 1.15.1.1, kit Ransod, Randox Laboratories, Crumlin, UK) in whole blood, glutathione peroxidase (GPx, EC 1.11.1.9, kit Ransel, Randox Laboratories, Crumlin, UK) in erythrocytes, reduced glutathione (GSH, Oxis, Portland, OR, USA) in erythrocytes, total antioxidant capacity of plasma (AOC, kit Total Antioxidant Status, Randox Laboratories, Crumlin, UK) were measured using commercial sets and the levels of plasma thiobarbituric acid reactive substances (TBARS) were obtained using the thiobarbituric acid reaction (modification by Jentzsch (Jentzsch et al. 1996)). We determined AOPP by a photometric assay (Witko-Sarsat et al. 1996). Activity of paraoxonase 1 (PON1, EC 3.1.1.2) was measured as the amount of hydrolyzed paraoxon by monitoring the absorbance increase at $410 \mathrm{~nm}$ and $37^{\circ} \mathrm{C}$ (increase of 4nitrophenol concentration). Results are expressed as U/l, where 1 unit is defined as $1 \mathrm{nmol}$ of 4-nitrophenol formed in 1 minute (Ferre et al. 2002, Hasselwander et al. 1998).

\section{Statistics}

The outcome measures (AST, ALT, GMT, SOD, GPx, GSH, AOC, TC, HDL, apoA, apoB, PON1, FbgTG, uCRP, Hcy, and AOPP) were tested for normality and normally distributed values were compared (initial values, after one month of white wine consumption and a month later) by analysis of variance (ANOVA) with repeated measures. For post-hoc comparisons Scheffé test was used. GMT, TAG, uCRP, Hcy, TBARS and AOPP were non-normally distributed, therefore Wilcoxon signed rank test for paired and Mann-Whitney $U$ test for unpaired comparisons were used. Participants were further divided into 2 groups (wine and beer consumers, there was no consumer of spirits) according to main consumed alcoholic beverage (more than $50 \%$ of total alcohol consumption and more than $10 \mathrm{~g}$ of ethanol 


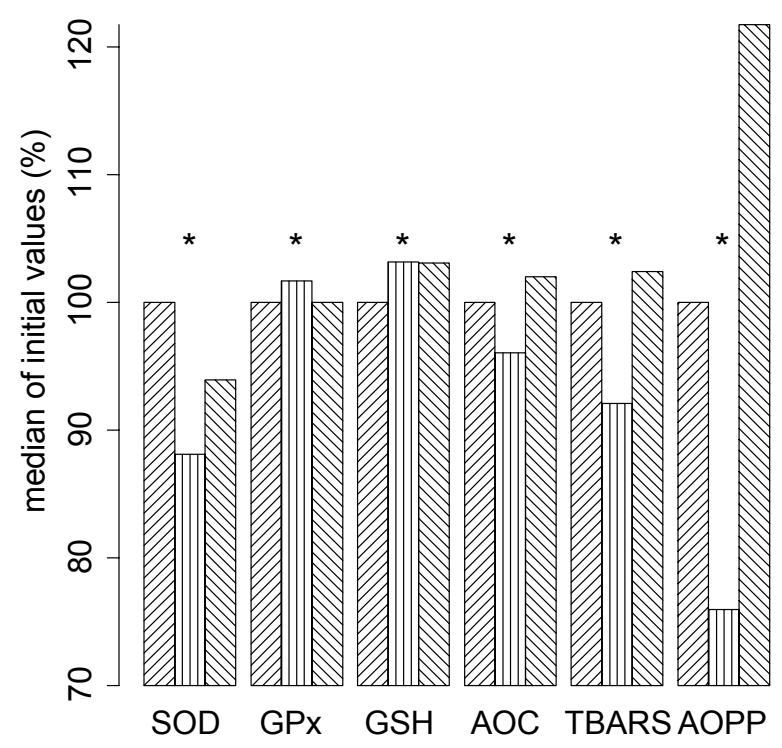

Fig. 1. Oxidative stress parameters. Data are expressed as percentage of median initial values. Each analyte (SOD = superoxide dismutase, $\mathrm{GPx}=$ glutathione peroxidase, $\mathrm{GSH}=$ reduced glutathione, $\mathrm{AOC}=$ total antioxidant capacity of plasma, TBARS = thiobarbituric acid reactive substances, AOPP = advanced oxidation protein products) is described in 3 adjacent columns: first column $=$ initial values, second column $=$ after WCP, third column $=$ a month after WCP. * statistically significant $(P<0.05)$ increase/decrease after WCP.

coming from the specific alcoholic beverage) as indicated by initial alcohol consumption questionnaire. These two groups $(9$ wine consumers [mean \pm S.D. percentage of total initial alcohol consumption 22.9 \pm 7.68 ] and 16 beer consumers $[31.94 \pm 18.60])$ were compared by the unpaired t-test (or Mann-Whitney $U$ test for nonparametric analysis) for changes in all followed parameters (values after wine consumption minus initial values). Pearson correlation coefficients were computed to determine associations between changes in outcome measures. $\mathrm{P}<0.05$ value was considered as statistically significant. Stepwise multiple regression with backward algorithm was used to select valuable predictors for final multiple regression model. All computations were performed with StatView software and $\mathrm{R}$ 2.1.0 (http://www.r-project.org).

\section{Results}

\section{Liver enzymes}

There was an increase in AST and ALT activities $(\mathrm{p}<0.05$ and $\mathrm{p}<0.005$, respectively) after the WCP and consecutive decrease after the next month $(\mathrm{p}<0.005$ and $\mathrm{p}<0.05$, respectively). However, all participants were found to have AST and GMT activities within reference ranges $(<0.67 \mu \mathrm{kat} / \mathrm{l}$ for AST and $<1.77$
Table 2. Oxidative stress parameters.

\begin{tabular}{lcll}
\hline & \multicolumn{3}{c}{ Visit } \\
& $\mathbf{0}$ & \multicolumn{1}{c}{$\mathbf{1}$} & \multicolumn{1}{c}{$\mathbf{2}$} \\
\hline $\operatorname{SOD}(\mathrm{U} / \mathrm{g} \mathrm{Hb})$ & $1280 \pm 95$ & $1133 \pm 100 * * *$ & $1200 \pm 119 \dagger \dagger$ \\
$\operatorname{GPx}(\mathrm{U} / \mathrm{g} \mathrm{Hb})$ & $58.5 \pm 8.1$ & $59.9 \pm 8.0 * *$ & $58.9 \pm 9.1 \dagger$ \\
$\operatorname{GSH}(\mathrm{mmol} / \mathrm{l})$ & $1.91 \pm 0.34$ & $1.97 \pm 0.28 *$ & $1.94 \pm 0.26)$ \\
$\operatorname{AOC}(\mathrm{mmol} / \mathrm{l})$ & $1.52 \pm 0.10)$ & $1.46 \pm 0.12 * * *$ & $1.53 \pm 0.11 \dagger \dagger$ \\
$\operatorname{TBARS}(\mu \mathrm{mol} / \mathrm{l})$ & $2.34 \pm 0.59$ & $2.21 \pm 0.52 *$ & $2.32 \pm 0.55)$ \\
AOPP $(\mu \mathrm{mol} / \mathrm{l})$ & $32.3 \pm 21.6$ & $23.7 \pm 10.8 * * *$ & $35.4 \pm 13.4 \dagger \dagger$ \\
\hline
\end{tabular}

Data are expressed as mean \pm S.D. Visit $0=$ initial values before wine consumption period (WCP); visit $1=$ values one day after WCP; visit $2=$ values one month after WCP. * (**, ***): Statistically significantly different from visit 0 values $-p<0.05$ $(p<0.01, p<0.001) . \quad+\quad(\dagger+,+\dagger+)$ : Statistically significantly different from visit 1 values $-p<0.05(p<0.01, p<0.001)$.

$\mu \mathrm{kat} / \mathrm{l}$ for GMT) after WCP. Visit 0 values of 8 volunteers (19\%) and 3 more participants (11 persons, $26 \%$ ) after WCP (Table 1) slightly exceeded the upper threshold for ALT $(<0.67 \mu \mathrm{kat} / \mathrm{l})$. There was a weak, but statistically significant positive correlation between the GMT and homocysteine change $(\mathrm{r}=0.36, \mathrm{p}<0.05$, change $=$ visit 1 minus visit 0 values).

\section{Oxidative stress parameters}

Daily one-month white wine intake was associated with an increase in GSH and GPx ( $<<0.05$ and $\mathrm{p}<0.005$, respectively) and a decrease in SOD, TBARS and AOPP ( $<<0.0001, p<0.05$ and $p<0.001$, respectively), which was generally followed by a return to initial values after one month (Fig. 1, Table 2). Surprisingly, AOC decreased $(p<0.001)$ after WCP and increased one month later $(\mathrm{p}<0.0001)$.

\section{Cardiovascular risk markers}

Serum HDL and apoA concentrations increased ( $<<0.0001$ and $p<0.005$, respectively) after WCP and decreased a month later $(\mathrm{p}<0.0001$ and $\mathrm{p}<0.05$, respectively). PON activities increased $(\mathrm{p}<0.001)$ after WCP, but remained increased a month later. There was a weak, but significant positive correlation between PON change and HDL change $(r=0.36, p<0.05$, change $=$ visit 1 minus visit 0 values). All other measured cardiovascular risk markers (BMI, blood pressure, TG, $\mathrm{TC}$, apoB, uCRP, fibrinogen) remained without any statistically significant changes (Table 1, Fig. 2). However, TG concentrations exceeded the upper reference limit $(1.7 \mathrm{mmol} / \mathrm{l})$ after $\mathrm{WCP}$ in 18 volunteers 


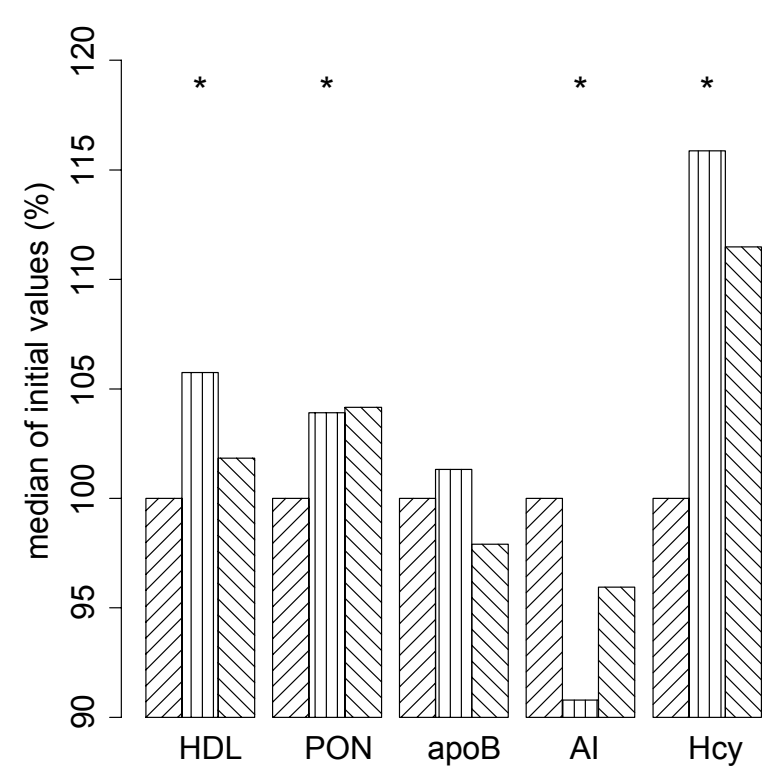

Fig. 2. Selected risk factors of atherosclerosis. Data are expressed as percentage of median initial values. Each analyte $(\mathrm{HDL}=\mathrm{HDL}$-cholesterol, $\mathrm{PON}=$ paraoxonase $1, \mathrm{apoB}=$ apolipoproteine $\mathrm{B}, \mathrm{AI}=$ atherogenic index calculated as follows: non-HDL-cholesterol/HDL-cholesterol, Hcy = homocysteine) is described in 3 adjacent columns: first column $=$ initial values, second column $=$ after WCP, third column $=$ a month after WCP. * statistically significant $(\mathrm{P}<0.05)$ increase/decrease after WCP.

(42\%) in comparison with 13 volunteers (30\%) before WCP. Nevertheless, there was a statistically significant negative correlation $(r=-0.71, p<0.0001)$ between initial values of TG and the change after WCP (values after WCP - initial values).

\section{Homocysteine concentrations}

Plasma homocysteine concentrations were markedly increased after WCP $(\mathrm{p}<0.0001$, vs. visit 0$)$ and decreased significantly ( $<0.01$, vs. visit 1$)$ a month later (Table 1, Fig. 2). The homocysteine levels remained unchanged or slightly decreased (from visit 0 to visit 1 ) in 5 participants $(12 \%)$ only. However, the increase was significantly lower $(\mathrm{p}<0.05)$ in volunteers from the beer drinkers group (median increase $1.35 \mu \mathrm{mol} / \mathrm{l}$ ) than the increase in the wine drinkers group (median increase $2.20 \mu \mathrm{mol} / \mathrm{l})$. For identification of important regressors (or confounders) of homocysteine change, we performed backward stepwise regression with homocysteine changes as dependent variables and initial age, BMI and homocysteine, classification as wine and beer drinkers, change in GMT and ALT as independent variables. This attitude resulted in final regression model with regressors listed in Table 3.
Table 3. Results of multiple regression model with homocysteine change as dependent variable and age, homocysteine concentration, classification as wine drinkers and change of GMT (change = visit 1 values minus visit 0 values).

\begin{tabular}{|c|c|c|c|}
\hline Regressor & $\begin{array}{l}\text { Regression } \\
\text { coefficient }\end{array}$ & S.E.M. & $\mathbf{p}$ \\
\hline Age & 0.043 & 0.0236 & 0.076 \\
\hline Homocysteine & -0.150 & 0.1084 & 0.176 \\
\hline Wine drinkers & 1.347 & 0.5383 & 0.017 \\
\hline Change of GMT & 5.816 & 2.2881 & 0.016 \\
\hline Adjusted $R^{2}$ & \multicolumn{2}{|c|}{0.25} & $\mathrm{p}=0.007$ \\
\hline
\end{tabular}

\section{Discussion}

Our data suggest that a moderate daily intake of white wine with dinner can have antioxidative and cardioprotective effects. The decrease in SOD with an increase in GPx in erythrocytes could lead to a lower burden of hydrogen peroxide and a higher rate of (lipid) hydroperoxide decomposition. The increased intracellular GSH provides a better reduction potential against reactive oxygen (and nitrogen) species (Rajdl et al. 2005). Moreover, the decrease in TBARS is suggestive that the whole process of lipid peroxidation is diminished by regular moderate white wine drinking. Lipid peroxidation is believed to have a crucial role in atherogenesis (Salonen 2000, Racek et al. 2005). In addition, the decrease of AOPP after WCP can be interpreted as diminished neutrophil activation and thus decreased oxidative stress (Yazici et al. 2004). Several studies have been unsuccessful in proving that white or red wine can provide effective antioxidant protection in vivo (Aviram and Fuhrman 2002, Cui et al. 2002, van der Gaag et al. $2000 \mathrm{~b}$ ), but there is general agreement that there are specific differences among different (red and white) wines that are caused mainly by the way in which grapes are cultivated and by the method of wine production (Aviram and Fuhrman 2002, Cui et al. 2002, Flesch et al. 1998). The wine used in this study was relatively rich in catechine, epicatechine, gallic acid and trans-resveratrol, so that its antioxidative effect was probable (Landrault et al. 2001, Moreno-Labanda et al. 2004). However, AOC of this wine was 3-5 times lower than in some commercially available red wines from Czech Republic (data not shown) and therefore the increase in plasma AOC need not be pronounced. Why plasma AOC decreased significantly after WCP remains unclear, but 
this is in agreement with a similarly designed study with white and red wines and champagne (Cartron et al. 2003). In summary, changes in the complex of measured intracellular antioxidative defense markers (SOD, GPX and especially GSH) and extracellular oxidative stress markers (TBARS, AOPP, with exception of AOC) suggest antioxidative effects of administered white wine. It is worth mentioning that recently published prospective double-blinded and placebo controlled studies did not confirm the hypothesis that supplementation of some antioxidative vitamins ( $\mathrm{E}$ and $\mathrm{C}$ ) and other antioxidants (e.g. selenium or $\beta$-carotene) or their combinations are effective in prevention or treatment of atherosclerotic complications (Stephens et al. 1996, Yusuf et al. 2000, Lonn et al. 2005)

The increase in HDL and apoA concentrations can be ascribed to the effect of ethanol. This is in accordance with results of other authors (Maclure 1993, Klatsky et al. 1997, Rimm et al. 1999, van der Gaag et al. 1999, Di Castelnuovo et al. 2002). Together with an increase in paraoxonase activity (van der Gaag et al. 1999, Aviram and Fuhrman 2002), HDL increase is believed to be the major cardioprotective effect of moderate alcohol intake. In our study, PON activities increased by $8 \%$ after one month of daily moderate alcohol consumption and remained on increased levels one month later. The failure to detect a decrease after cessation of wine consumption can be explained by delayed (in comparison with HDL and apoA) kinetics of PON (Sierksma et al. 2002). Although relatively nontoxic substrates, such as phenylacetate, can be used to determine PON activity, the hydrolysis of paraoxon seems most closely related to the inverse relationship with coronary heart disease (Mackness et al. 2003). Interestingly, it seems that initial values of TG negatively correlate with the increase of TG after WCP.

Several contradictory studies dealing with the effect of moderate alcohol intake on homocysteine levels have appeared recently (van der Gaag et al. 2000a, Mayer et al. 2001, Dixon et al. 2002, Ganji and Kafai 2003). Both the increase and the decrease of homocysteine levels, as a consequence of moderate alcohol drinking, have not yet been elucidated. However, several theories, including interference of alcohol with the absorption and metabolism of vitamins $\mathrm{B}_{6}, \mathrm{~B}_{12}$ and folic acid (van der Gaag et al. 2000a, Bleich et al. 2001, de la Vega et al. 2001) or the homocysteine lowering effect of betaine that is added to some red wines (Mar and Zeisel 1999), are available. In our interventional study we proved an increase in fasting homocysteine levels after a month of moderate white wine consumption, which is in agreement with two similar interventional studies (van der Gaag et al. 2000a, Bleich et al. 2001). As we were interested in finding the most probable predictors of the homocysteine increase, we performed multiple regression analysis that revealed preexisting preference of wine and change of GMT as significant predictors. However, explanation of changes in homocysteine after a month of moderate white wine consumption was not the aim of our study and the number of participants in each drinking pattern group (wine and beer drinkers) was quite limited. Thus the results of multiple regression should be considered as preliminary. The statistically significant difference between the participants that consumed more than $50 \%$ of ethanol as beer before starting WCP and participants that consumed more than $50 \%$ of ethanol as wine (red or white) indicates that beer could have some homocysteinemaintaining (or even lowering) properties (van der Gaag et al. 2000a, Mayer et al. 2001, Mennen et al. 2003). Changes in GMT reflect individual reactions on chronic ethanol ingestion and thus we can hypothesize that regular moderate consumption of white wine interferes with hepatic metabolism of homocysteine or substances important in its metabolism. Some experimental data suggest that the disruption of homocysteine metabolism by chronic ethanol ingestion could be caused by inhibition of methionine synthase (EC 2.1.1.13) with acetaldehyde (Barak et al. 2002). Betaine homocysteine methyl transferase (EC 2.1.1.5) is an alternative enzyme to methionine synthase, thus betaine supplementation is a promising approach to prevent the homocysteine increase after regular moderate alcohol consumption $(\mathrm{Ji}$ and Kaplowitz 2003, Olthof et al. 2003, Balkan et al. 2004). However, the main limitation of our study was the absence of control (placebo) group. The changes in extra alcohol consumed during the whole study were minor and probably clinically insignificant. That is why we can partly consider visit 0 and visit 2 results as paired controls to the white wine period.

In conclusion, our data from a non-placebo controlled trial suggest that some white wines can have antioxidative effects in vivo, moderate daily consumption of white wine is associated with cardioprotective (increase of HDL, apoA and PON) and potentially proatherogenic effects (increase of homocysteine levels). The consumption of a particular type of alcoholic beverage may have important effects on homocysteine concentrations. 


\section{Acknowledgements}

This study was conducted with the support of the grant GAUK \# 121/2004/C and Bohemia Sekt Company, Starý Plzenec, Czech Republic. The analysis of wine compounds was provided by the Department of
Landscape Ecology, the Academy of Sciences of the Czech Republic in České Budějovice and the analytical laboratory, Bohemia Sekt Company, Starý Plzenec, Czech Republic.

\section{References}

AVIRAM M, FUHRMAN B: Wine flavonoids protect against LDL oxidation and atherosclerosis. Ann N Y Acad Sci 957: 146-161, 2002.

BALKAN J, OZTEZCAN S, KUCUK M, CEVIKBAS U, KOCAK-TOKER N, UYSAL M: The effect of betaine treatment on triglyceride levels and oxidative stress in the liver of ethanol-treated guinea pigs. Exp Toxicol Pathol 55: 505-509, 2004.

BARAK AJ, BECKENHAUER HC, TUMA DJ: Methionine synthase. A possible prime site of the ethanolic lesion in liver. Alcohol 26: 65-67, 2002.

BASAŘOVÁ G, ČERNÁ I: Methods for polyphenol determination and their practical importance (in Czech). Kvasný průmysl 20: 121, 1974.

BELLÍ N, MARÍN S, SANCHIS V, RAMOS A: Review: Ochratoxin a (OTA) in wines, musts and grape juices: Occurrence, regulations and methods of analysis. Food Sci Technol Int 8: 325-335, 2002.

BLEICH S, BLEICH K, KROPP S, BITTERMANN HJ, DEGNER D, SPERLING W, RUTHER E, KORNHUBER J: Moderate alcohol consumption in social drinkers raises plasma homocysteine levels: a contradiction to the 'French paradox? Alcohol Alcohol 36: 1891-1892, 2001.

CARTRON E, FOURET G, CARBONNEAU M, LAURET C, MICHEL F, MONNIER L, DESCOMPS B, LEGER CL: Red-wine beneficial long-term effect on lipids but not on antioxidant characteristics in plasma in a study comparing three types of wine-description of two O-methylated derivatives of gallic acid in humans. Free Radic Res 37: 1021-1035, 2003.

CUI J, TOSAKI A, BERTELLI AAE, BERTELLI A, MAULIK N, DAS DK: Cardioprotection with white wine. Drugs Exp Clin Res 28: 1-10, 2002.

DE LA VEGA MJ, SANTOLARIA F, GONZALEZ-REIMERS E, ALEMAN MR, MILENA A, MARTINEZ-RIERA A, GONZALEZ-GARCIA C: High prevalence of hyperhomocysteinemia in chronic alcoholism: the importance of the thermolabile form of the enzyme methylenetetrahydrofolate reductase (MTHFR). Alcohol 25: 59-67, 2001.

DEMROW HS, SLANE PR, FOLTS JD: Administration of wine and grape juice inhibits in vivo platelet activity and thrombosis in stenosed canine coronary arteries. Circulation 91: 1182-1188, 1995.

Di CASTELNUOVO A, ROTONDO S, IACOVIELlo L, DONATI MB, DE GAETANO G: Meta-analysis of wine and beer consumption in relation to vascular risk. Circulation 105: 2836-2844, 2002.

DIXON JB, DIXON ME, O'BRIEN PE: Reduced plasma homocysteine in obese red wine consumers: a potential contributor to reduced cardiovascular risk status. Eur J Clin Nutr 56: 608-614, 2002.

FERRE N, CAMPS J, PRATS E, VILELLA E, PAUL A, FIGUERA L, JOVEN J: Serum paraoxonase activity: a new additional test for the improved evaluation of chronic liver damage. Clin Chem 48: 261-268, 2002.

FLESCH M, SCHWARZ A, BOHM M: Effects of red and white wine on endothelium-dependent vasorelaxation of rat aorta and human coronary arteries. Am J Physiol 275: H1183-H1190, 1998.

GANJI V, KAFAI MR: Demographic, health, lifestyle, and blood vitamin determinants of serum total homocysteine concentrations in the third national health and nutrition examination survey, 1988-1994. Am J Clin Nutr 77: 826-833, 2003.

GOLDBERG IJ, MOSCA L, PIANO MR, FISHER EA: AHA science advisory: wine and your heart: a science advisory for healthcare professionals from the Nutrition Committee, Council on Epidemiology and Prevention, and Council on Cardiovascular Nursing of the American Heart Association. Circulation 103: 472-475, 2001. 
HASSELWANDER O, MCMASTER D, FOGARTY DG, MAXWELL AP, NICHOLLS DP, YOUNG IS: Serum paraoxonase and platelet-activating factor acetylhydrolase in chronic renal failure. Clin Chem 44: 179-181, 1998.

JENTZSCH AM, BACHMANN H, FURST P, BIESALSKI HK: Improved analysis of malondialdehyde in human body fluids. Free Radic Biol Med 20: 251-256, 1996.

JI C, KAPLOWITZ N: Betaine decreases hyperhomocysteinemia, endoplasmic reticulum stress, and liver injury in alcohol-fed mice. Gastroenterology 124: 1488-14499, 2003.

KALOUSOVÁ M, ZIMA T, TESAŘ V, DUSILOVÁ-SULKOVÁ S, ŠKRHA J: Advanced glycoxidation end products in chronic diseases-clinical chemistry and genetic background. Mutat Res 579: 37-46, 2005.

KLATSKY AL, ARMSTRONG MA, FRIEDMAN GD: Red wine, white wine, liquor, beer, and risk for coronary artery disease hospitalization. Am J Cardiol 80: 416-20, 1997.

LANDRAULT N, POUCHERET P, RAVEL P, GASC F, CROS G, TEISSEDRE PL: Antioxidant capacities and phenolics levels of French wines from different varieties and vintages. J Agric Food Chem 49: 3341-3348, 2001.

LEFEVRE G, BELJEAN-LEYMARIE M, BEYERLE F, BONNEFONT-ROUSSELOT D, CRISTOL JP, THEROND P, TORREILLES J: Evaluation of lipid peroxidation by measuring thiobarbituric acid reactive substances (in French). Ann Biol Clin (Paris) 56: 305-319, 1998.

LONN E, BOSCH J, YUSUF S, SHERIDAN P, POGUE J, ARNOLD JMO, ROSS C, ARNOLD A, SLEIGHT P, PROBSTFIELD J, DAGENAIS GR: Effects of long-term vitamin E supplementation on cardiovascular events and cancer: a randomized controlled trial. JAMA 293: 1338-1347, 2005.

MACKNESS B, DURRINGTON P, MCELDUFF P, YARNELL J, AZAM N, WATT M, MACKNESS M: Low paraoxonase activity predicts coronary events in the Caerphilly Prospective Study. Circulation 107: 2775 $2779,2003$.

MACLURE M: Demonstration of deductive meta-analysis: ethanol intake and risk of myocardial infarction. Epidemiol Rev 15: 328-351, 1993.

MAR MH, ZEISEL SH: Betaine in wine: answer to the French paradox? Med Hypotheses 53: 383-385, 1999.

MAYER OJ, ŠIMON J, ROSOLOVÁ H: A population study of the influence of beer consumption on folate and homocysteine concentrations. Eur J Clin Nutr 55: 605-609, 2001.

MENNEN LI, DE COURCY GP, GUILLAND J, DUCROS V, ZAREBSKA M, BERTRAIS S, FAVIER A, HERCBERG S, GALAN P: Relation between homocysteine concentrations and the consumption of different types of alcoholic beverages: the French supplementation with antioxidant vitamins and minerals study. Am J Clin Nutr 78: 334-338, 2003.

MORENO-LABANDA JF, MALLAVIA R, PEREZ-FONS L, LIZAMA V, SAURA D, MICOL V: Determination of piceid and resveratrol in Spanish wines deriving from Monastrell (Vitis vinifera L.) grape variety. J Agric Food Chem 52: 5396-5403, 2004.

NG CJ, SHIH DM, HAMA SY, VILLA N, NAVAB M, REDDY ST: The paraoxonase gene family and atherosclerosis. Free Radic Biol Med 38: 153-163, 2005.

OLTHOF MR, VAN VLIET T, BOELSMA E, VERHOEF P: Low dose betaine supplementation leads to immediate and long term lowering of plasma homocysteine in healthy men and women. $J$ Nutr 133: 4135-4138, 2003.

PEREZ DD, STROBEL P, FONCEA R, DIEZ MS, VASQUEZ L, URQUIAGA I, CASTILLO O, CUEVAS A, SAN MARTIN A, LEIGHTON F: Wine, diet, antioxidant defenses, and oxidative damage. Ann N Y Acad Sci 957: 136-145, 2002.

RAJDL D, RACEK J, TREFIL L, NOVOTNÝ Z, STOŽICKÝ F, STEINEROVÁ A, SIALA K: Markers and oxidative stress in diabetic mothers and their infants during delivery. Physiol Res 54: 429-436, 2005.

RACEK J, RUSNÁKOVÁ H, TREFIL L, SIALA K: The influence of folate and antioxidants on homocysteine levels and oxidative stress in patients with hyperlipidaemia on hyperhomocysteinemia. Physiol Res 54: 87-95, 2005.

RAO MN, MARMILLOT P, GONG M, PALMER DA, SEEFF LB, STRADER DB, LAKSHMAN MR: Light, but not heavy alcohol drinking, stimulates paraoxonase by upregulating liver mRNA in rats and humans. Metabolism 52: 1287-1294, 2003. 
RIMM EB, WILLIAMS P, FOSHER K, CRIQUI M, STAMPFER MJ: Moderate alcohol intake and lower risk of coronary heart disease: meta-analysis of effects on lipids and haemostatic factors. BMJ 319: 1523-1528, 1999.

SAIJA A, SCALESE M, LANZA M, MARZULLO D, BONINA F, CASTELLI F: Flavonoids as antioxidant agents: importance of their interaction with biomembranes. Free Radic Biol Med 19: 481-486, 1995.

SALONEN JT: Markers of oxidative damage and antioxidant protection: assessment of LDL oxidation. Free Radic Res 33 (Suppl): S41-S46, 2000.

SIERKSMA A, VAN DER GAAG MS, VAN TOL A, JAMES RW, HENDRIKS HFJ: Kinetics of HDL cholesterol and paraoxonase activity in moderate alcohol consumers. Alcohol Clin Exp Res 26: 1430-1435, 2002.

STEPHENS NG, PARSONS A, SCHOFIELD PM, KELLY F, CHEESEMAN K, MITCHINSON MJ: Randomised controlled trial of vitamin e in patients with coronary disease: Cambridge heart antioxidant study (CHAOS). Lancet 347: 781-786, 1996.

TRUELSEN T, GRONBAEK M, SCHNOHR P, BOYSEN G: Intake of beer, wine, and spirits and risk of stroke: The Copenhagen City Heart Study. Stroke 29: 2467-2472, 1998.

TŘíSKA J, VRCHOTOVÁ N, KYSELÁKOVÁ M, BALÍK J, VEVERKA J, TOTUŠEK J, LEFNEROVÁ D: The distribution of resveratrol and other phenolic compounds in the berries and stems of the red vine. In: OIV Congress 2004. The International Organization of Vine and Wine, Vienna, Austria, 2004, pp P-4.04 (8 pages) (CD ROM).

TSELEPIS A, LOURIDA E, TZIMAS P, ROUSSIS I: Comparative antioxidant effectiveness of white and red wine and their phenolic extracts towards low-density lipoprotein oxidation. Food Biotechnology 19: 1-14, 2005.

VAN DER GAAG MS, VAN TOL A, SCHEEK LM, JAMES RW, URGERT R, SCHAAFSMA G, HENDRIKS HF: Daily moderate alcohol consumption increases serum paraoxonase activity, a diet-controlled, randomised intervention study in middle-aged men. Atherosclerosis 147: 405-410, 1999.

VAN DER GAAG MS, UBBINK JB, SILLANAUKEE P, NIKKARI S, HENDRIKS HF: Effect of consumption of red wine, spirits, and beer on serum homocysteine. Lancet 355: 1522, 2000a.

VAN DER GAAG MS, VAN DEN BERG R, VAN DEN BERG H, SCHAAFSMA G, HENDRIKS HF: Moderate consumption of beer, red wine and spirits has counteracting effects on plasma antioxidants in middle-aged men. Eur J Clin Nutr 54: 586-591, 2000b.

WHELAN AP, SUTHERLAND WHF, MCCORMICK MP, YEOMAN DJ, DE JONG SA, WILLIAMS MJA: Effects of white and red wine on endothelial function in subjects with coronary artery disease. Intern Med J 34: 224228, 2004.

WITKO-SARSAT V, FRIEDLANDER M, CAPEILLERE-BLANDIN C, NGUYEN-KHOA T, NGUYEN AT, ZINGRAFF J, JUNGERS P, DESCAMPS-LATSCHA B: Advanced oxidation protein products as a novel marker of oxidative stress in uremia. Kidney Int 49: 1304-1313, 1996.

YAZICI C, KOSE K, CALIS M, DEMIR M, KIRNAP M, ATES F: Increased advanced oxidation protein products in Behcet's disease: a new activity marker? Br J Dermatol 151: 105-111, 2004.

YUSUF S, DAGENAIS G, POGUE J, BOSCH J, SLEIGHT P: Vitamin E supplementation and cardiovascular events in high-risk patients. The Heart Outcomes Prevention Evaluation Study Investigators. N Engl J Med 342: 154$160,2000$.

\section{Corresponding author}

D. Rajdl, Institution of Clinical Chemistry and Hematology, Charles University Hospital, Alej Svobody 80, 30460 Plzeň, Czech Republic. E-mail: rajdl@fnplzen.cz 